\title{
Atuação da equipe multiprofissional em saúde, no cenário da pandemia por Covid 19
}

\author{
${ }^{1}$ Anuska da Silva Maia Guimarães \\ ${ }^{2}$ Thaynara Gabriella Silva Cunha \\ ${ }^{3}$ Thainara Alves dos Santos \\ ${ }^{4}$ Lucyana Bertoso de Vasconcelos Freire
}

1 Assistente Social Residente do Programa de Residência Multiprofissional em Nefrologia pela ESCS/FEPECS.

2 Enfermeira Residente do Programa de Residência Multiprofissional em Nefrologia pela ESCS/FEPECS.

3 Nutricionista Residente do Programa de Residência Multiprofissional em Nefrologia pela ESCS/FEPECS.

4.Tutora do Programa de Residência Multiprofissional em Nefrologia da ESCS/FEPECS/SES. Mestre em Enfermagem pela Universidade de Brasília- UnB.

\section{RESUMO}

Introdução: Diante do contexto da pandemia e crescente disseminação do COVID-19, se faz necessário a atuação de equipe multiprofissional na assistência à saúde, para proporcionar assistência integral e ampliar a divulgação de informações completas e embasadas no estabelecimento de medidas de prevenção e controle para enfrentamento da transmissão. Objetivo: Apresentar reflexão teórica acerca da abordagem da equipe multiprofissional em Nefrologia no cenário do COVID-19. Método: Estudo teórico reflexivo no qual foram utilizados trabalhos referentes à infecção por Coronavírus e à atuação multiprofissional com foco na assistência de nutrição, enfermagem e assistência social. Resultados: O novo coronavírus apresenta alta transmissibilidade e, por isso, é necessário implementar medidas de prevenção e controle, que contam com a capacitação de uma equipe multiprofissional no estabelecimento das estratégias a serem seguidas e orientadas. Conclusão: A abordagem multiprofissional possibilita pensar em ações estratégicas conjuntas por diversos profissionais que têm um objetivo em comum, compreender o paciente com suspeita ou confirmação de COVID 19 e vincular as ações a todas as esferas de direitos, o que permite alcançar melhores respostas às suas demandas em sua totalidade, e não na perspectiva de fragmentação.

Palavras-chave: coronavírus, equipe de assistência ao paciente, assistência integral à saúde. 


\title{
Performance of the multidisciplinary health team during the Covid-19 pandemic scenario
}

\begin{abstract}
Introduction: In the context of the pandemic context and the growing dissemination of COVID-19, a multidisciplinary team in health care is needed to provide comprehensive assistance and expand the dissemination of complete information based on the establishment of control control measures and for coping transmission. Objective: to present the theoretical reflection on the approach of the multidisciplinary team in Nephrology in the scenario of COVID-19. Method: Reflective theoretical study in which studies related to coronavirus infection and multiprofessional performance were used, focusing on nutrition assistance, nursing and social assistance. Results: The new coronavirus has high transmissibility and, therefore, it is necessary to implement control and control measures, which contaminate the ability of a multiprofessional team to establish strategies that are followed and guided. Conclusion: A multiprofessional approach makes it possible to think of joint strategic actions by several professionals who have a common goal, including the patient with suspicion or the verification of COVID 19 and link as actions to all the rights rules, or what allows to follow the best answers to your questions. demands its openness, and not from the perspective of fragmentation.
\end{abstract}

Keywords: coronavirus, patient care team, comprehensive health care. 


\section{INTRODUÇÃO}

O coronavírus 19 é um vírus respiratório emergente que se enquadra como um desafio à saúde pública, surgiu em Wuhan, na China, em novembro de 2019, e no prazo de dois meses foram confirmados milhares de casos e inúmeros óbitos. Em março de 2020 houve disseminação para uma centena de países causando doença respiratória e óbitos em massa. Devido à velocidade de disseminação, severidade e dificuldades para contenção, a Organização Mundial de Saúde (OMS) declarou pandemia pelo novo coronavírus em 11 de março de $2020 .{ }^{1}$

É classificado como um beta Coronavírus do mesmo subgênero da Síndrome Respiratória do Oriente Médio (MERS), porém de outro subtipo. Definido como um RNA vírus responsável pela manifestação clínica do COVID 19, caracterizado como uma zoonose, e foi nomeado como SARS-CoV-2. ${ }^{2}$

Apresenta alta transmissibilidade através de gotículas e aerossóis ou por contato com pessoas ou superfícies contaminadas. Possui período de incubação de até 15 dias. $^{2}$ Os sintomas vão de leves com tosse, fadiga, febre, anorexia, cefaleia, rinorreia, anosmia, diarreia e vômitos, a graves como dispneia progressiva, piora do estado geral, febre $>38^{\circ}$ por mais de três dias, e geralmente tem início de 2 a 14 dias após a exposição. ${ }^{3}$

Segundo o último boletim epidemiológico do $\mathrm{COE}$ (Centro de Operações de Emergência em Saúde Pública), até 26 de abril de 2020, foram confirmados 2.940 .993 casos de COVID-19 com 203.822 óbitos no mundo. Os Estados Unidos da América é o país com maior número de casos e óbitos ( 960.896 e 54.265, respectivamente). O Brasil é o $11^{\circ}$ em número de casos com 61.888 e também o $11^{\circ}$ em número de óbitos com 4.205 casos, até a data de publicação do boletim. ${ }^{4}$

Existem grupos que se enquadram em quadro de risco e maior vulnerabilidade ao ser infectado com o vírus, pessoas com idade > 65 anos, Hipertensão Arterial Sistêmica, Diabetes 
Mellitus, imunossupressão, neoplasia, Doença Pulmonar Obstrutiva Crônica, tabagismo, hepatopatia crônica, Doença Renal Crônica e profissionais da saúde. ${ }^{3}$

A infecção se desenvolve inicialmente com a entrada do vírus no organismos pelas vias de transmissão e chegada ao sistema respiratório, onde se acopla ao receptor ACE2 existente na membrana do pneumócito II e assim entra na célula, em seguida o vírus libera o RNA, o qual é usado no mecanismo de transcrição dos ribossomos para sintetizarem mais RNA e partículas virais que irão compor sua cápsula e após ser replicação o vírus é liberado na luz dos alvéolos. ${ }^{5}$

Os serviços de saúde devem estar preparados para detectar precocemente pacientes suspeitos ou confirmados de infecção pelo 2019-nCov, de modo a adotar medidas de controle que evitem a propagação do vírus, a serem seguidas por esses pacientes, podendo utilizar de alertas visuais, como placas e banners, na entrada e em locais estratégicos dos serviços. ${ }^{1}$

A detecção precoce se embasa na abordagem clínica da síndrome gripal, que se apresenta com febre $>37,8^{\circ}$ aferida ou referida, tosse, dor de garganta e dificuldade respiratória. Com esta identificação já é possível fornecer ao paciente suspeito máscara cirúrgica, meios para higienização das mãos (álcool gel ou água e sabão), e conduzir a pessoa para uma área separada ou específica para isolamento respiratório, com janelas abertas, ar-condicionado desligado e porta fechada. ${ }^{1}$

As medidas de controle devem ser implementadas antes da chegada do paciente ao serviço de saúde, cujo meio utilizado para este fim pode ser o contato telefônico, na chegada, triagem, espera do atendimento e durante toda a assistência prestada. ${ }^{6}$

Dentre as estratégias inclusas nas medidas de prevenção e controle estão identificação precoce de sintomáticos respiratórios na triagem, já providenciando diante da identificação de caso suspeito separação dos demais pacientes em sala de espera separada ou quarto isolado, em 
que o paciente precisará manter 1 (um) metro de distância de outros casos que eventualmente tenham que aguardar ou ser alocados no mesmo recinto, com portas fechadas, bem ventilado e com a presença de lenços descartáveis para etiqueta respiratória, lixeiras com tampa acionada por pedal, dispensadores de álcool gel e pias com água e sabão líquido e papéis toalha descartáveis. ${ }^{1}$

É importante também providenciar o fluxo deste paciente com encaminhamento ao serviço de referência com comunicação prévia, e caso seja decidido pela equipe que o paciente ficará isolado no domicílio durante 14 dias, seguindo orientações de etiqueta respiratória, higiene frequente das mãos, manter distância de 1 metro dos demais, não compartilhar objetos de uso pessoal, promover limpeza e desinfecção frequente de objetos e superfícies com os quais teve contato e procurar o serviço de saúde para hospitalização em caso de apresentação de sintomas de complicação. ${ }^{1}$

É reconhecida a necessidade da implementação integral da abordagem de uma equipe multiprofissional na assistência à saúde. O trabalho desta formação proporciona ao paciente e familiares uma visão mais ampla do problema ao oferecer conhecimento e motivação para superar desafios. ${ }^{7}$

Toda a equipe está inclusa no cenário do COVID-19 na assistência à saúde, por isso é importante a atuação de todos para orientação e estabelecimento das medidas de controle e prevenção frente a rápida disseminação do novo coronavírus. Com a busca da capacitação e obtenção de conhecimento técnico científico acerca dos equipamentos de proteção individual a serem utilizados no atendimento a esses casos, bem como quais orientações fornecer a população para estabelecer um fluxo de atendimento adequado a esses pacientes com recomendações eficazes para diminuir a transmissão. 
A disseminação do COVID-19 ocorreu de forma rápida causando pânico e propagação de muitas informações fragmentadas e muitas vezes equivocadas por todos os meios de comunicação. A população diante do desespero ocasionado buscou comprar exageradamente insumos de proteção e alimentação, o que desencadeou um cenário em que há exagero em alguns modos de proteção e outros, também muito importantes e eficientes no combate ao vírus, que foram esquecidos, como a higiene frequente das mãos, fundamental como meio de prevenção.

Frente a esta problemática, a equipe multiprofissional deve veicular informações completas, concretas, baseadas em recomendações por autoridades sanitárias, bem como implementar estas orientações na sua atuação profissional.

Os estudos e referências com relação ao tema do novo coronavírus, principalmente na área da nutrição e assistência social ainda são escassos, gerando dificuldade na elaboração de materiais completos. Devido a este panorama, surgiu a motivação de elaborar este artigo, no qual buscou-se unir as referências encontradas no assunto abordado para elaboração de um material completo com as informações pertinentes voltadas para cada uma das profissões inclusas na pesquisa.

\section{MÉTODO}

Estudo teórico reflexivo construído no decorrer da atuação das autoras no Programa de Residência Multiprofissional em Nefrologia da Escola Superior de Ciências da Saúde (ESCS/FEPECS/SES). Para tanto, apoiou-se nos trabalhos teóricos referentes ao objeto de estudo, em textos acerca da atuação multiprofissional, nos escritos de pesquisadores reconhecidos nas áreas específicas da enfermagem, nutrição e serviço social, além de artigos que aplicaram a assistência multiprofissional no contexto do Coronavírus e em outros cenários de atuação. 
Para aprofundamento e pesquisa acerca do tema, realizou-se busca nas edições atuais acerca da pandemia do Coronavírus no âmbito nacional e internacional, como publicações advindas da OMS, Ministério da Saúde, Anvisa e nas bases de dados PUBMED/MEDLINE, LILACS, SCIELO, utilizando a seguinte estratégia de busca: (“Nutrição e COVID-19 ") AND ("Manejo nutricional da COVID-19") AND ("Manejo COVID-19") AND ("Triagem COVID19") AND ("Protocolo COVID-19") AND ("Saúde do trabalhador e COVID-19") AND (“Saúde mental e COVID-19”) AND (“Serviço Social e COVID-19”) AND (“Atuação do assistente social e COVID-19”) AND (“Exercício profissional diante da pandemia do COVID19”).O processo de reflexão iniciou-se com a leitura analítica dos trabalhos selecionados, seguido de leitura comparativa e crítica, discussão de vivências práticas nos cenários de atuação multiprofissional que culminou com este ensaio teórico reflexivo.

\section{RESULTADOS}

O novo coronavírus é um agente causador de séries de casos de pneumonia por todo o mundo, que pode cursar sem complicações ou em estágio grave. Tem alta transmissibilidade e provoca síndrome respiratória aguda que varia de casos leves (cerca de 80\%) a casos muito graves com insuficiência respiratória (5 a 10\%) e sua letalidade tem variado conforme a faixa etária e condições clínicas associadas. ${ }^{2}$

Considerando a ocorrência de transmissão comunitária, é recomendado o trabalho de detecção por meio da abordagem sindrômica do problema. O foco é voltado a apresentação clínica como síndrome gripal ou síndrome respiratória aguda grave (SRAG), com base no protocolo de influenza do Ministério da Saúde. Um dos agentes etiológicos de maior magnitude responsável também por estas duas síndromes é o vírus da influenza, cuja abordagem pragmática unifica as condutas referentes a esses dois agentes. ${ }^{2}$ 
A transmissão ocorre por meio do contato com pessoas sintomáticas, principalmente quando não há higiene das mãos, e através de gotículas respiratórias oriundas de pacientes. Apresenta espectro clínico amplo, com a principal sintomatologia sendo febre $>37,8^{\circ}$ por cerca de três dias, tosse, fadiga, dispneia, mal estar e mialgia, sintomas respiratórios do trato superior, raramente sintomas gastrintestinais. ${ }^{1} \mathrm{O}$ paciente com síndrome gripal tem febre de início súbito, tosse ou dor de garganta, acompanhados por um dos seguintes sintomas: cefaleia, mialgia ou artralgia. ${ }^{1}$

Ainda seguindo este manual de orientações, caso exista contato de qualquer natureza com casos suspeitos ou confirmados de infecção pelo novo coronavírus implementar precauções adicionais para gotículas e contato. Já em procedimentos geradores de aerossol, como em aspiração ou intubação traqueal, ventilação invasiva e não invasiva, indução de escarro e coletas de amostras nasotraqueais, é utilizada precaução para aerossol, com uso adicional da máscara N95 ou PFF2, de preferência em local com isolamento respiratório ou quarto com portas fechadas, ar condicionado desligado e janelas abertas, com número restrito de profissionais, adequadamente equipados. ${ }^{6}$

Como parte do processo de controle de infecção, o serviço de saúde deve disponibilizar aos pacientes insumos e suprimentos bem distribuídos e de fácil acesso para higiene das mãos e etiqueta respiratória, que inclui dispensadores de álcool gel, pias com sabão líquido, lenços de papel e lixeiras com tampa de abertura sem contato manual. ${ }^{6}$

Conforme recomendação da ANVISA todos os profissionais da saúde no atendimento a qualquer paciente deve utilizar medidas de precaução padrão, assumindo que podem estar potencialmente contaminados ou infectados. São elas higiene das mãos com álcool ou água e sabão nos 5 momentos preconizados pela OMS, gorro, óculos de proteção ou protetor facial, máscara cirúrgica, avental e luvas de procedimento. ${ }^{6}$ 
A multiprofissionalidade diz respeito ao trabalho conjunto de várias categorias que culmina na articulação das ações e cooperação mútua com foco em um objetivo comum. A eficiência e eficácia da assistência à saúde demandam uma modalidade de trabalho em equipe com a conexão das diferentes ações e distintos profissionais. ${ }^{7}$

Portanto cada profissional tem seu importante papel frente ao combate da rápida disseminação do vírus, de modo que deve estar capacitado a seguir as recomendações embasadas nas autoridades sanitárias competentes, bem como orientar a população acerca das medidas de prevenção e controle para reduzir a transmissão do vírus.

\section{Nutrição}

O combate à pandemia do COVID-19 se tornou o grande desafio atual, e a terapia é parte fundamental do cuidado integral na atenção ao paciente crítico. A maioria dos pacientes contaminados tem sido tratados em casa, em isolamento domiciliar. Entretanto, uma parte destes pacientes complicam e necessitam serem hospitalizados, e cerca de $5 \%$ precisam de terapia intensiva. Neste subgrupo, as complicações mais frequentes são a disfunção respiratória e seguida da disfunção renal. ${ }^{8}$

O espectro clínico da doença de COVID-19 parece amplo, abrangendo assintomáticos, infecção leve do trato respiratório superior e pneumonia grave com insuficiência respiratória, com muitos pacientes sendo hospitalizados e exigindo cuidados subintensivos ou intensivos. ${ }^{9}$

Vários fatores que levaram à progressão da pneumonia por COVID-19 foram além de idade, tabagismo, temperatura corporal máxima e insuficiência respiratória. A proteína $\mathrm{C}$ reativa e a albumina sérica demonstraram ser marcadores independentes de prognóstico. Embora a albumina não seja afetada exclusivamente pelo estado nutricional, faz parte de vários índices de triagem nutricional e está associado a condições nutricionais. Curiosamente, baixos níveis de pré-albumina, outro marcador de desnutrição, demonstrou prever a progressão da 
doença para insuficiência respiratória e ventilação mecânica. Essa evidência reforça o conceito de que distúrbios nutricionais devem ser sistematicamente e urgentemente gerenciados em pacientes afetados pelo COVID-19, considerando também que a resposta imune se mostrou enfraquecida pela inadequação da nutrição. ${ }^{9}$

Os poucos artigos disponíveis que mencionaram cuidados de suporte no COVID-19 recomendam que o estado nutricional deve ser avaliado em todos os pacientes infectados na admissão hospitalar e os pacientes em risco nutricional devem receber apoio nutricional o mais cedo possível, principalmente aumento da ingestão de proteínas por suplementos nutricionais orais. $^{10}$

Recomenda-se a realização da triagem nutricional em até 48 horas após a admissão hospitalar em todos os pacientes, porém considerando a pandemia atual do COVID-19, é recomendado, entretanto, evitar o contato físico do nutricionista com os pacientes, é sugerido então que durante a internação dos pacientes com COVID-19 sejam incluídas perguntas para triagem nutricional, sempre que possível. ${ }^{8}$

Para avaliação, acompanhamento e evolução dos pacientes, o nutricionista pode valerse de dados secundários de prontuário, de contato telefônico com o paciente e do intermédio de membros da equipe multiprofissional que já estejam em contato direto com esses pacientes. ${ }^{10}$

Caso seja necessária visita presencial, essa deve ser realizada conforme regimentos internos do Serviço de Controle de Infecção Hospitalar da instituição no que diz respeito ao uso dos Equipamentos de Proteção Individual (EPIs), de acordo com as recomendações do Ministério da Saúde, OMS e CDC. ${ }^{11}$

Nos pacientes que apresentem fatores de risco que aumentem o risco nutricional em si, a terapia nutricional deve ser considerada, por meio de suplementação oral em um primeiro momento, até que as necessidades nutricionais estejam sendo supridas em sua totalidade pela 
dieta via oral exclusiva, visto que estes indivíduos apresentam, frequentemente, inapetência, disgeusia (perda de paladar) e anosmia (perda de olfato), afetando diretamente a aceitação alimentar. $^{11}$

Em pacientes graves, a Nutrição Enteral (NE) é a via preferencial e é sugerido que seja iniciada entre 24 e 48 horas. No caso de contraindicação da via oral e/ou enteral, a Nutrição Parenteral (NP) deve ser iniciada o mais precocemente possível. A BRASPEN sugere considerar o uso de NP suplementar após 5 a 7 dias em pacientes que não conseguirem atingir aporte calórico proteico $>60 \%$ por via digestiva.

É importante ter atenção também sobre os procedimentos desempenhados por copeiros e auxiliares que entram em contato com pacientes, para a segurança dos pacientes e desses profissionais. $^{10}$

É de fundamental importância que os nutricionistas e a EMTN (equipe multiprofissional de terapia nutricional) estejam envolvidos no desenvolvimento dos protocolos de atendimento e na indicação de TN e devem estar sempre alinhados com os profissionais de saúde a fim de rastrear pacientes em risco nutricional. ${ }^{8}$

Apesar das dificuldades da pandemia atual, é importante ressaltar que os pacientes acompanhados pela EMTN devem seguir recebendo o suporte nutricional e atenção que necessitam, sem nenhuma repercussão negativa em seu tratamento. ${ }^{8}$

\section{Enfermagem}

O enfermeiro assume posição de liderança devido a sua formação, o que coloca o profissional como protagonista no combate a transmissão do novo coronavírus. A relevância da enfermagem se destaca na detecção e avaliação dos casos suspeitos, não apenas em razão de sua capacidade técnica, mas também por fazerem parte do maior número de profissionais da área da saúde, e serem a única categoria que está nas 24 horas junto ao paciente. ${ }^{12}$ 
As medidas de prevenção e controle de infecções devem ser aplicadas nos serviços de saúde pelos profissionais para evitar ou reduzir ao máximo a transmissão de microrganismos durante a realização de qualquer assistência à saúde. ${ }^{13}$

A via de transmissão sugerida atualmente ocorre por meio de gotículas (expelidas durante a fala, tosse ou espirro) e por contato direto com pessoas infectadas ou indireto por meio das mãos, objetos ou superfícies contaminadas. ${ }^{6}$

Desta forma, as medidas de prevenção e controle devem ser estabelecidas antes da chegada do paciente ao serviço, na chegada, na triagem, espera, atendimento e durante toda a assistência prestada ${ }^{13}$.A Organização Mundial de Saúde (OMS) estabeleceu requisitos mínimos para a implantação da prevenção e controle de infecção:

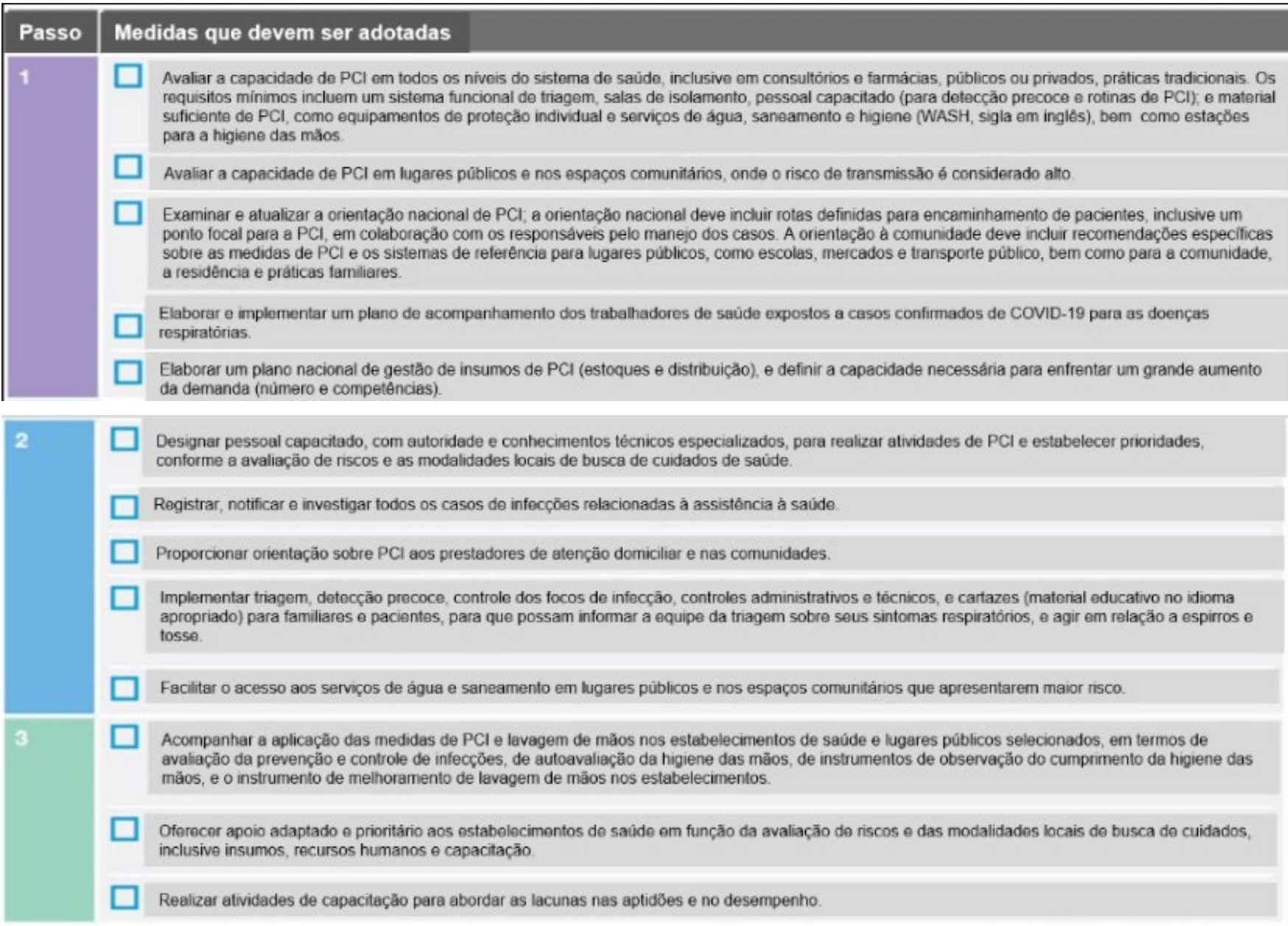

Figura 1: Requisitos mínimos para implantação da prevenção e controle de infecção por COVID-19 (OMS) 
A enfermagem deve implementar sistema de triagem para detectar pacientes com suspeita de infecção pelo novo coronavírus (SARS-Cov-2) antes do registro do paciente. Garantir que um questionário simples seja feito a todos os pacientes sobre a presença de sintomas respiratórios ou contato com possíveis casos confirmados. ${ }^{6}$

Diante disso, providenciar o isolamento rápido de pacientes com sintomas de infecção por COVID-19 ou outra infecção respiratória. Outra conduta importante é impedir que estes pacientes suspeitos não fiquem aguardando atendimento junto aos demais. Destinar um espaço bem ventilado para que estes casos em espera fiquem afastados e com fácil acesso a suprimentos e orientações de higiene e etiqueta respiratória e higiene das mãos. Fornecer a estas pessoas máscara cirúrgica na entrada dos serviços e salas de espera adequadas. Devem permanecer nessa área até a consulta ou encaminhamento a unidade hospitalar adequada. ${ }^{6}$

Neste ambiente além da máscara cirúrgica, que deve ser utilizada durante toda a permanência na unidade, devem ser dispostos para uso lenços descartáveis para etiqueta respiratória e lixeira com pedal que acione a tampa para desprezar os lenços utilizados. É necessário posicionar dispensadores com preparação alcoólica e pias com água e sabão líquido com papel toalha para a higiene das mãos, por exemplo, após uso de lenços descartáveis na higiene respiratória. ${ }^{6}$

Dentre as medidas de etiqueta respiratória a serem orientadas aos pacientes, além das já citadas anteriormente, estão o uso do braço flexionado para cobrir nariz e boca ao tossir ou espirrar, evitar tocar olhos, nariz e boca com as mãos não higienizadas. ${ }^{1}$

Elaborar materiais educativos com orientações acerca do distanciamento social em vigor, etiqueta respiratória e higiene das mãos que possam ser dispostos pela unidade de saúde como alertas visuais aos clientes, assim como esclarecer que ainda não há droga efetiva no tratamento da doença. ${ }^{1}$ 
Aos profissionais de saúde e apoio estão atribuídos cuidados como reforçar a limpeza e desinfecção de objetos e superfícies, principalmente maçanetas, interruptores, corrimões, botões em elevadores. Evitar tocar superfícies próximas ao paciente e aquelas fora do ambiente próximo ao paciente, com luvas, EPI's ou mãos contaminadas. Providenciar limpeza e desinfecção de equipamentos utilizados no atendimento de casos suspeitos ou confirmados. Utilizar EPI's adequados se necessário contato de menos de 1 metro de pacientes suspeitos ou confirmados para a infecção por COVID-19. Em caso de necessidade de encaminhar o paciente para outro serviço de saúde, sempre notificar previamente o serviço referenciado. ${ }^{6}$

Fora da área de assistência aos clientes com suspeita ou confirmação da infecção o profissional de saúde não deve circular utilizando os EPI's, devem ser removidos imediatamente após a saída do quarto, enfermaria ou sala de isolamento. Porém se o profissional sai de um local para atendimento de outro caso suspeito ou confirmado é necessário trocar apenas avental e luvas, após higiene das mãos, mantendo gorro, óculos/protetor facial e máscara. ${ }^{6}$

Os casos suspeitos ou confirmados devem ser mantidos em quarto isolado com portas fechadas e bem ventilado (janelas abertas). Em procedimentos geradores de aerossol é recomendada unidade de isolamento respiratório com pressão negativa e filtro HEPA (High Efficiency Particulate Arrestance), se não houver este local, no ambiente anteriormente citado de isolamento deverão permanecer número restrito de profissionais, todos utilizando a máscara N95 ou PFF2 ou superior. ${ }^{6}$

$\mathrm{Na}$ eventualidade de não haver quartos isolados para cada um dos pacientes pode ser utilizada acomodação em coorte, ou seja, separar em uma mesma enfermaria pacientes infectados pelo COVID-19. Essa coorte pode ser organizada em todas as unidades ou setores que forem receber casos suspeitos ou confirmados. Deve ser mantida distância mínima de 1 metro entre os leitos e restringir o número de acessos a esse local. ${ }^{6}$ 
A unidade de saúde deve manter o registro de quem entrou no quarto para prestar a assistência, o acesso é restrito aos profissionais de saúde responsáveis pela atenção a saúde. O quarto deve permanecer com as portas fechadas com cartazes imediatamente na porta com as precauções a serem seguidas para entrada: padrão, gotículas, contato e aerossóis, este último em situações específicas já citadas. Imediatamente antes do local de isolamento devem ser disponibilizadas condições para higiene das mãos, EPI apropriado e mobiliário para guarda e descarte de EPI. ${ }^{6}$

Os profissionais destinados a prestar assistência a esses pacientes devem ser escalados para trabalhar somente no coorte, durante todo seu turno de trabalho, não devendo circular em outras áreas ou prestar assistência a outros pacientes. ${ }^{6}$

Os pacientes suspeitos ou confirmados que não necessitem de hospitalização deverão receber orientações acerca do controle de infecção, prevenção de transmissão para contatos e sinais de alerta para possíveis complicações. A presença de qualquer sinal de alerta deve determinar retorno e hospitalização imediata do paciente. É fundamental que a enfermagem realize avaliação individualizada do caso, verificando se o paciente apresenta condições ou fatores de risco e se o ambiente residencial é adequado, bem como se o paciente é capaz de seguir as medidas de precaução recomendadas pela equipe de saúde. ${ }^{1}$

O SARS-COV-2 pode estar associado a diferentes síndromes clínicas: doença branda, pneumonia sem complicações, pneumonia severa, síndrome da angústia respiratória aguda, sepse e choque séptico.

Na admissão do paciente infectado pelo novo coronavírus são coletados exames laboratoriais de hematologia e bioquímica e ECG para monitorar complicações, como lesão hepática aguda, lesão renal aguda, lesão cardíaca aguda ou choque. ${ }^{1}$ 
O manejo clínico da síndrome respiratória tem base na administração de oxigenoterapia suplementar imediatamente a pacientes com síndrome respiratória aguda grave (SRAG) e dificuldade respiratória, hipoxemia ou choque com alvo em SpO2 $>94 \%$, tratamento conservador de fluidos intravenosos cautelosamente quando não houver evidência de choque, coleta de culturas uma hora antes de iniciar o antibiótico, que em caso de sepse deve ser iniciado em uma hora após a avaliação inicial, promover monitoramento regular dos sinais vitais para identificação rápida de sinais de complicações clínicas como insuficiência respiratória e sepse de progressão rápida. ${ }^{1}$

Com relação ao uso dos equipamentos de proteção individual (EPI's) os profissionais de saúde responsáveis pelo atendimento de casos suspeitos ou confirmados devem realizar higiene das mãos com preparação alcoólica frequentemente, utilizar gorro, óculos de proteção ou protetor facial, máscara, avental impermeável de mangas longas e luvas de procedimento. A máscara N95, PFF2 ou superior, deve ser utilizada sempre que for realizar procedimento gerador de aerossol, como intubação ou aspiração traqueal, ventilação não invasiva, ressuscitação cardiopulmonar, ventilação manual antes da intubação, indução de escarro, coletas de amostras nasotraqueais e broncoscopias. ${ }^{1}$

Aos profissionais de apoio, como da limpeza, manutenção, nutrição, assistência social e outros, são recomendados higiene das mãos com preparação alcóolica frequentemente, gorro, óculos de proteção ou protetor facial, máscara cirúrgica, avental impermeável de mangas longas, luvas de procedimentos. ${ }^{1}$

No uso correto do equipamentos de proteção individual (EPI) há necessidade de na colocação seguir a ordem de higiene das mãos, máscara, óculos, gorro, higiene das mãos, avental, higiene das mãos e por último as luvas, já na retirada a frequência da higiene aumenta, pelo fato de que a contaminação de profissionais da saúde ocorreu em larga escala neste momento, portanto, tem início com o primeiro par de luvas, higiene das mãos, avental, nova 
higiene, gorro, repetindo a higiene, óculos, mais uma vez higienizando e por fim a máscara, seja cirúrgica ou N95 sem tocar na parte exterior contaminada. ${ }^{3}$

Os serviços de saúde devem implementar políticas não punitivas para permitir que o profissional de saúde que apresente sintomas de infecção respiratória seja afastado do trabalho. ${ }^{1}$

É dever da instituição fornecer os EPI's específicos aos profissionais que atuam nos casos suspeitos ou confirmados de COVID-19. Os demais devem seguir os procedimentos de rotina utilizando os equipamentos de costume em suas áreas de atuação. ${ }^{14}$

$\mathrm{O}$ artigo 22 do código de ética dos profissionais de enfermagem estabelece que o profissional pode se recusar a executar atividades que não sejam de sua competência técnica, científica, ética e legal ou que não ofereçam segurança ao profissional, à pessoa, à família e à coletividade. Portanto, há respaldo ético, mas é importante que haja registro de elementos que comprovem a falta de condições de segurança e que a chefia seja comunicada de imediato. Além de ser necessário realizar denúncia ao conselho. ${ }^{14}$

Frente ao cenário desta pandemia muitas pessoas sofrem impacto psicossocial que está associado a magnitude do problema e ao grau de vulnerabilidade da pessoa, que apresenta reações consideradas normais associadas a uma situação anormal.

A pandemia impacta as pessoas de diferentes maneiras, como desconfiança no processo de gestão e coordenação dos protocolos de biossegurança, necessidade de se adaptar a esses novos protocolos, falta de equipamentos de proteção individual em algumas estruturas sanitárias, risco de ser infectado e infectar os outros, sintomas comuns de outras afecções que podem ser confundidos com a infecção pelo COVID-19, preocupação com familiares devido a necessidade do distanciamento social. ${ }^{15}$ 
Dentre as reações comportamentais mais comuns em meio ao novo problema de saúde pública estão alterações ou distúrbios de apetite ou de sono, conflitos interpessoais, violência (doméstica ou voltada a profissionais de saúde). ${ }^{15}$

Para lidar com as mudanças de humor e crises é importante investir em exercícios que auxiliem na redução do nível de estresse, manter contato virtual com a rede socioafetiva, garantir pausas sistemáticas em local tranquilo entre os turnos de trabalho, evitar o uso de tabaco, álcool e outras drogas para lidar com as emoções, reduzir o tempo ouvindo ou lendo coberturas midiáticas, estimular o espírito solidário e incentivar a participação da sociedade. No caso de nenhuma das orientações obter efeito é importante procurar o profissional de saúde mental e atenção psicossocial. ${ }^{14}$

\section{Serviço social}

Segundo os Parâmetros para atuação do Assistente Social na Política de Saúde, o objetivo do Serviço Social na área da saúde, "passa pela compreensão dos determinantes sociais, econômicos e culturais que interferem no processo saúde-doença e na busca de estratégias político-institucionais para o enfrentamento dessas questões". ${ }^{16} \mathrm{O}$ profissional de Serviço Social tem a função de mediar junto à equipe de saúde, traduzindo a realidade social dos pacientes, buscando atuar nas demandas postas em sua totalidade, conforme dispõe o art. $3^{\circ}$ da Lei 8080/90:

A saúde tem como fatores determinantes e condicionantes, entre outros, a alimentação, a moradia, o saneamento básico, o meio ambiente, o trabalho, a renda, a educação, o transporte, o lazer e o acesso aos bens e serviços essenciais; os níveis de saúde da população expressam a organização social e econômica do País. ${ }^{17}$

Conforme prevê o Código de Ética do/a Assistente Social, artigo $3^{\circ}$, alínea d, o/a assistente social tem como compromisso ético o dever de "participar de programas de socorro à população em situação de calamidade pública, no atendimento e defesa de seus interesses e 
necessidades" ${ }^{18}$, sendo, portanto requisitado para trabalhar em equipe multiprofissional, realizando atendimentos, encaminhamentos, coleta de dados, cadastramento, orientação sobre direitos e deveres, entre outras intervenções. ${ }^{19}$

A atuação profissional deve ser pautada por direitos e deveres que constam nas normativas que orientam e norteiam o/a assistente social, a saber: o Código de Ética Profissional e a Lei de Regulamentação da profissão, sendo vedada a execução de atividades que não competem a este, como a realização de triagens de casos clínicos de pacientes sintomáticos, bem como outras ações que não são atribuições e competências do assistente social. ${ }^{19}$

Diante do contexto de pandemia do COVID-19, se faz necessário apresentar à população respostas que direcionem ao atendimento de suas necessidades imediatas, sendo estas as mais diversas: as que necessitam de contínuo atendimento, haja vista o contexto de desigualdade, bem como as resultantes da pandemia do COVID-19, que vão da prevenção (isolamento social - alimentação, água, material de higiene), à atenção aos diagnosticados com o COVID-19, como também aos seus familiares e comunidade. ${ }^{19}$

Nesse sentido, as intervenções devem ter como premissa a orientação social, que tem como objetivo a ampliação do acesso dos indivíduos e da coletividade aos direitos sociais. Assim sendo, frente à pandemia da COVID-19 se constitui essencial a dimensão socioeducativa da profissão dada a urgência de se construir estratégias e ações para assegurar o acesso à informação e orientação sobre os serviços públicos, para o alcance de informações claras e oficiais sobre enfrentamento à pandemia, sua prevenção e tratamento pela população, e especialmente na defesa e viabilização de acesso aos programas, serviços e benefícios sociais. E com essa direção, esta dimensão é fundamentalmente necessária na construção de estratégias no processo de desburocratização do acesso aos serviços e benefícios emergenciais no âmbito institucional. ${ }^{20}$ 


\section{CONCLUSÃO}

A pandemia do novo coronavírus rapidamente se estabeleceu como grave problema de saúde pública devido ao seu alto potencial de transmissibilidade e intensa disseminação, ocupando leitos hospitalares em uma velocidade preocupante em um cenário que logo apresentou desafios para suprir e atender a demanda emergente.

A atuação da equipe multiprofissional no manejo dos casos acometidos e vulneráveis é fundamental para atuação tanto na promoção da saúde, quanto na assistência aos pacientes acometidos por COVID-19 e Síndrome Respiratória Aguda Grave.

\section{REFERÊNCIAS BIBLIOGRÁFICAS}

1. Ministério da Saúde. (2020). Protocolo de Tratamento do Novo Coronavírus (2019-nCOV). Brasília, Distrito Federal, Brasil.

2. Unasus. (2020). Qualificação - Doenças ocasionadas por vírus respiratórios emergentes, incluindo o COVID-19. Fonte: Una-sus.

3. Unifesp. (2020). Manual de Condutas COVID-19.

4. Boletim Epidemiológico Especial - COE COVID 19. Secretária de Vigilância em Saúde . 26 de Abril de 2020.

5. Vaduganathan, M., Vardeny, O., T. M., McMurray, J. J., Pfeffer, M. A., \& Solomon , S. D. (2020). Renin-Angiotensin-Aldosterone System Inhibitors in Patients with Covid-19. The New England Journal of Medicine.

6. Anvisa. (30 de Janeiro de 2020). Orientações para serviços de Saúde: Medidas de prevenção e controle que devem ser adotadas durante a assistencia aos casos suspeitos ou confirmados de infecçao pelo novo Coronavírus (SARS-CoV-2). Brasil . 
7. Peduzzi, M. (2001). Equipe multiprofissional de saúde: conceitoe tipologia. Revista de Saúde Pública, 103-109.

8. Fuganti Campos , L., Alves Barreto , P., Duprat Ceniccola, G., Brescovici Nunes de Matos, L., Martins Saiva Figueredo Zambeli , C., \& Gouveia Castro, M. (2020). Parecer BRASPEN/ AMIB para o Enfrentamento do COVID-19 em Pacientes Hospitalizados. Braspen Journal , 35.

9. Early nutritional supplementation in non-critically ill patients hospitalized for the 2019 novel coronavirus disease (COVID-19): Rationale and feasibility of a shared pragmatic protocol. Caccialanza, Riccardo, et al. 26 de Março de 2020, Journal Pre-proof.

10. Conselho Federal de Nutricionistas . (20 de Março de 2020). Recomendações do CFN Boas Práticas para Atuação do Nutricionista e do Técnico em Nutrição e Dietética Durante a Pandemia do Novo Coronavírus (COVID-19). Brasilía, Brasil.

11. Fraga Piovacari , S. M., Correa Gaetano Santos , G. F., Amaral Santana , G., Scacchetti, T., \& Gouveia Castro , M. (2020). Fluxo de assistência nutricional para pacientes admitidos com COVID-19 e SCOVID-19 em unidade hospitalar. Braspen Journal , 6-8.

12. Cofen publica nota de esclarecimento sobre o coronavirus (COVID-19). Conselho Federal de Enfermagem . Brasilia : s.n., 12 de Março de 2020.

13. Prevenção e controle de infecções (PCI) causadas pelo novo coronavirus (COVID-19). Organização Mundial da Saúde. 2020.

14. Covid-19: tire suas dúvidas relacionadas a EPIs e outros temas . Conselho Regional de São Paulo . São Paulo : s.n., 2020.

15. 4. Saúde Mental e A atenção Psicossocial na Pandemia COVID-19. Fiocruz. 2020.

16. Conselho Federal de Serviço Social . (2010). Parâmetros para Atuação de Assistentes Sociais na Política de Saúde. Série: Trabalho e Projeto Profissional nas Políticas Sociais. Brasília. 
17. Brasil. Lei no 8.080, de 19 de setembro de 1990. Dispõe sobre as condições para a promoção, proteção e recuperação da saúde, a organização e o funcionamento dos serviços correspondentes e dá outras providências. Diário Oficial da União 1990; 19 set.

18. Conselho Federal de Serviço Social. (2012). Código de Ética do Assistente Social e Lei 8.662/93. Acesso em 12 de Abril de 2020, disponível em www.cfess.org.br/arquivos/CEP_CFESS-SITE.pdf

19. Conselho Regional de Serviço Social - $12^{\text {a }}$ Região . (2020). Orientações sobre a atuação de Assistentes Sociais em razão da pandemia do no coronavírus - Covid-19. Acesso em 20 de Abril de 2020, disponível em http://cress-sc.org.br/wp content/uploads/2020/03/Orienta\%C3\%A7\%C3\%B5es-COVID.pdf

20. Conselho Regional de Serviço Social - 9a Região . (2020). Orientação do CRESS-SP para assistentes sociais sobre o exercício profissional diante da pandemia do coronavírus COVID19. Fonte: http://cress-sp.org.br/wp-content/uploads/2020/03/ORIENTACOES-CRESSSPCOVID-19.pdf. 